\title{
Bachelor of Arts
}

National Cancer Institute

\section{Source}

National Cancer Institute. Bachelor of Arts. NCI Thesaurus. Code C71345.

A bachelor's degree in the liberal arts, usually awarded for studies in the social sciences or humanities. 